\title{
Genomic Analyses of Cryptobiotic Tardigrades
}

\author{
Brahim Mali, Markus Grohme, Weronika Wełnicz, Thomas Dandekar, \\ Martina Schnölzer, Dirk Reuter, Ralph O Schill and Marcus Frohme
}

\section{Zusammenfassung}

Techniken der Genomanalyse, speziell das transkriptionelle Profiling, erlauben uns, Genexpression innerhalb eines und zwischen verschiedenen Organismen zu untersuchen.

Wir nutzen als Modell Tardigraden, auch bekannt als Bärtierchen, um das Phänomen der Kryptobiose besser zu verstehen. Die ausgetrockneten Tiere können Jahre überdauern. Wenn man Wasser hinzugibt, rehydrieren die Tiere und werden wieder zum Leben erweckt. In unserem Labor untersuchen wir die Genexpression als Antwort auf das Austrockenen und Rehydrieren mittels Bibliotheken Exprimierter Sequenz Tags (ESTs), Repräsentativer Differenz Analyse und Mikroarray-Untersuchungen. Die molekulare Analyse des komplexen Phänomens und seiner Regulation auf Ebene der Gene wird es ermöglichen, Techniken für die Konservierung und Stabilisierung von biologischem Material in trockenem Zustand zu entwickeln.

\section{Summary}

Genomics technologies, especially transcriptional profiling, allows comparisons of gene expression within and across different organisms. By the use of the model group Tardigrada, also known as water bear, we try to understand the phenomenon of cryptobiosis. The dry organisms can survive for years without water. When re-exposed to water, the animals rehydrate and come back to life. The expression of genes in response to dehydratation and rehydratation is being examined in our laboratory through the generation of expressed sequence tags (ESTs), representational difference analysis (RDA) and subsequent microarray analysis. Molecular dissection of this complex phenomenom, including gene regulation, will allow the development of techniques for preservation and stabilisation of biological materials in a dried state.

\section{Introduction}

Many organisms possess the ability to survive extreme desiccation by entering into a state of suspended animation known as anhydrobiosis [1-2]. This state in which metabolism is not detectable is also known as cryptobiosis [3]. In extreme conditions of dehydration, anhydrobiotic organisms are able to adopt a metabolic dormancy. In that sense it is not »alive«, yet neither is it »dead « since suitable rehydration produces an obviously living organism. Once in dry state these organisms are highly resistant to environmental challenge, such as exposure to extremes temperature, radiation and pressure [4] as they may remain dormant for a long period [5]. Later they can resume their normal metabolic functions on rehydration.

Anhydrobiosis has been adapted during evolution by many organisms, from prokaryote [6] to eukaryote, especially, rotifers, nematodes and tardigrades [7]. Furthermore, plant seeds and vegetative tissues of certain higher plants have also the ability to exhibit anhyd- robiosis [8-9]. However, such phenomena have never been seen in higher organisms - i. e. vertebrates.

Anhydrobiosis is dependent on series of complex physiological adaptations, but a number of components appear to be important in protecting these organisms from desiccation damage such as the highly hydrophilic LEA proteins [10-12] and non-reducing disaccharides like trehalose [13-15].

Tardigrades, also known as water bears were first described by the german pastor J. A. E. Goeze in 1773 . They are usually less than $0.5 \mathrm{~mm}$ in length, have four pairs of legs (Fig. 1) and are either carnivorous or herbivorous. There are more than 900 different species living on land, in fresh water and in the sea [16]. Terrestrial tardigrades live in the thin film of water on the surface of moss, lichens, algae, and other plants and depend on water to remain active and complete their life cycle. They have been studied for their fascinating ability to perform cryptobiosis and consequently as a potential model animal for studying tolerance and survival of multicellular organisms to a variety of extreme 
environmental conditions [17]. Very recently they were even used to study extraterrestrial conditions in a space mission [18].

Although there are several physiological and ecological studies on tardigrades, only limited sequence information has been published so far, and no other genomic and molecular data are available regarding anhydrobiotic tardigrades. As part of FUNCRYPTA project (Functional Analysis of Dynamic Processes in Cryptobiotic Tardigrades) investigating gene and protein expression in the anhydrobiotic tardigrade Milnesium tardigradum (Fig. 1), we have generated 20,000 ESTs (expressed sequence tags) from 2 cDNA libraries of animals in active (alive) and inactive (dry) states.

Furthermore a molecular subtraction technique representational difference analysis of cDNA - aims to identifiy differentially expressed genes.

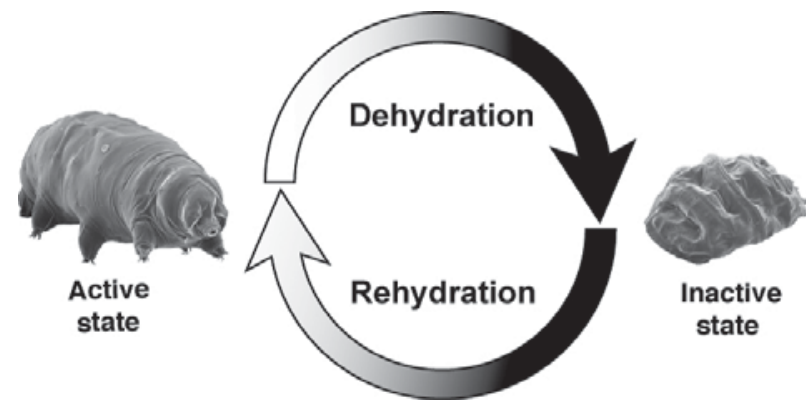

Fig. 1: The tardigrade Milnesium tardigradum on the way from an active to an anhydrobiotic state (inactive state) and back to an active stage again.

\section{Material and methods}

Milnesium tardigradum specimens used in this study, were provided by our FUNCRYPTA partner in Stuttgart. For each stadium (active and inactive) we used 600 animals that were frozen at $-80^{\circ} \mathrm{C}$ until the RNA isolation step and cDNA synthesis.

Obtaining high quality, intact RNA is the first and the most critical step in performing cDNA library construction. Due to the fragility of the RNA, extreme caution should be taken to avoid RNA degradation by ribonuclease (RNases) contamination. Therefore most of the RNA isolation procedure takes place in a strong denaturant (guanidium thiocyanate, SDS, phenol) that renders RNases inactive. Total RNA isolated was quantified by Nanodrop spectrophotometer and qualified with normal agarose gel and the Agilent Bioanalyzer.

Synthesis of first strand cDNA from RNA templates is catalyzed by viral reverse transcriptase in the presence of oligo(dT) 18 which anneals selectively on the poly(A) tail of mRNA. The first strand of cDNA is directly used as a template in PCR amplification. The amplified PCR products were analyzed by agarose gel electrophoresis. Sufficient cDNA was obtained after 18 PCR cycles. After digestion of the amplified cDNA with SfiI restriction enzyme, products smaller than 300 bp were removed by column chromatography.

The resulting cDNAs were directionally cloned into the Sfil-digested pDNR-Lib plasmid vector (Clontech) and transformed into Escherichia coli competent cells (Invitrogen) by electroporation. Following $1 \mathrm{~h}$ growth in a rich medium at $37^{\circ} \mathrm{C}$, cells were plated on LB agar medium containing chloramphenicol antibiotic and incubated overnight at $37{ }^{\circ} \mathrm{C}$. Colonies were picked with a colony-picking robot (Genetix) into 384-well plates. After overnight incubation at $37{ }^{\circ} \mathrm{C}$, the 384 well plates were stored at $-80^{\circ} \mathrm{C}$. One cDNA library was generated for each of the tardigrade stages (active and inactive).

Expressed sequence tag (EST) sequencing was undertaken for the purpose to discover anhydrobiotic genes. Initially, two cDNA libraries were constructed (active and inactive). A total of 10,000 clones (5,000/state) were analyzed by sequencing from the 5 ' end. Blast searches were conducted at the bioinformatics department in Würzburg (FUNCRYPTA partner).

We used representational difference analysis (RDA), which couples substractive hybridization to PCR-mediated kinetic enrichment [19], to identify differentially expressed genes between active and inactive tardigrades. cDNA for RDA was prepared from both states. After generation of representations three cycles of subtractive hybdridisation and amplification followed. Cloning of the difference products and subsequent sequencing led to potential candidate genes.

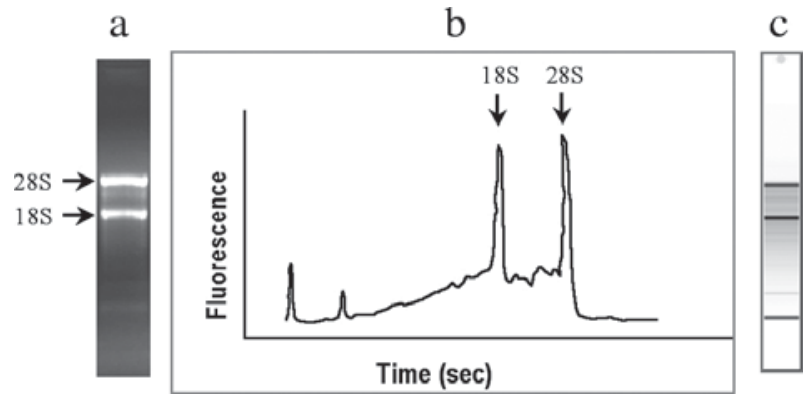

Fig. 2: Qualitative analysis of total RNA extracted from tardigrades. a) $28 \mathrm{~S}$ and $18 \mathrm{~S}$ rRNA separated by agarose gel electrophoresis (150 ng total RNA loaded). b) Electropherogram data from the Agilent 2100 bioanalyzer (1ng total RNA loaded) showing $18 \mathrm{~S}$ and $28 \mathrm{~S}$ rRNA peak profiles as well as a gel-like image (c). 


\section{Results}

Agarose gel electrophoresis (Fig. 2a) shows intact total RNA consisting mainly of two ribosomal RNA bands, $28 \mathrm{~S}$ and $18 \mathrm{~S}$. Their corresponding bands should appear sharp on a gel electrophoresis and the $28 \mathrm{~S}$ band should be approximately twice as bright as the $18 \mathrm{~S}$ band. In gene expression analysis, the quantity of RNA obtained is limited, thus the sensitivity of detection is very important. With the use of microcapillary electrophoresis, the Bioanalyzer is more sensitive than classical gel electrophoresis, and only as little as $100 \mathrm{pg}$ total RNA is needed to perform the analysis and thus saving most of the valuable sample. The output of this method is a diagram that displays fluorescence as a function of time, with small molecules appearing at the left side of the graph. Illustration of this by RNA quality is in Fig. 2b,c (good quality). Higher sensitivity allows detection of less abundant fractions of total RNA that are not visible by agarose electrophoresis.

Using total RNA prepared from active and inactive tardigrade, ds cDNAs were synthesized using the SMART PCR cDNA Synthesis Kit (Clontech). The quality of PCR product was checked by electrophoresis on a $1.1 \%$ agarose gel. A homogeneous smear of each PCR product ranging from 250 to $3,000 \mathrm{bp}$ in size was obtained (Fig. 3), showing the complex nature of the ds cDNAs which were used in the construction of the EST and RDA libraries.

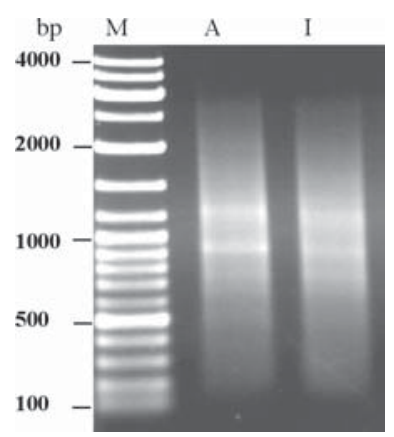

Fig 3: Agarose gel electrophoresis (1.1\%) of amplified SMART-prepared cDNA from Tardigrade. M: DNA ladder Mix., A: Tardigrade Active cDNA, I: Tardigrade Inactive CDNA, bp: base pair DNA

Two cDNA libraries were constructed from $M$. tardigradum (active and inactive). From these two libraries, a total of 10,000 clones were randomly selected, sequenced and analyzed. A total of 7,000 high-quality Expressed Sequence Tags (EST) sequences were generated from the 10,000 clones. The average length of the ESTs is $500 \mathrm{bp}$ ranging from 150 to $2,000 \mathrm{bp}$. These quality ESTs were further assembled into 3,800 unique ESTs. The 7,000 ESTs have been deposited to the Tardigrade analyzer software made especially for analysing the tardigrade genome and proteome [20].

The entire ESTs were subjected to a search for sequence homology in the GenBank DNA and EST database by BLAST. Blast results show mainly two groups of ESTs. The first gave hits to known genes and the second consisted of those ESTs having no corresponding or homologous sequence in the databases which can considered as putative novel cDNAs.

The difference products obtained after each cycle of subtractive hybdridisation and amplification (DP1, DP2 and DP3) are shown in Figure 4. The difference product showing a »smear « with some distinct bands was obtained only after the third round of enrichment (DP3). The DP products were excised from each gel and the DNA was purified and cloned. Approximately 30 clones were analysed each.
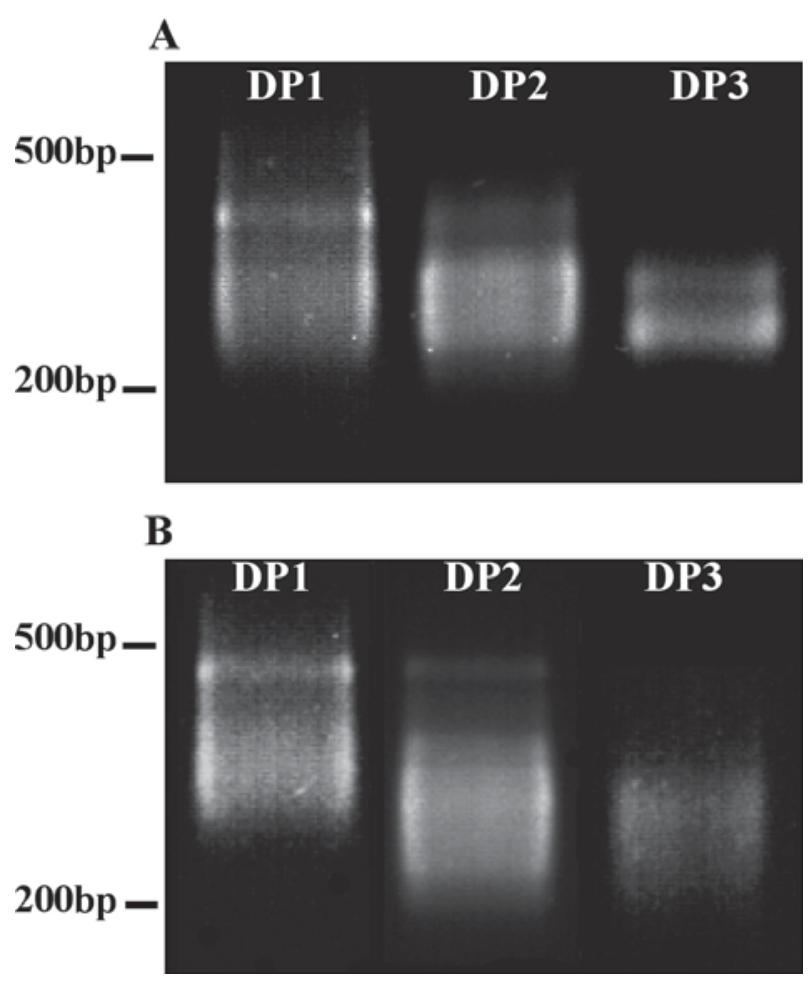

Fig. 4: Agarose gel electrophoresis of representations and difference products identified by RDA. Difference products after one two and three rounds of subtraction/amplification (DP1, DP2 and DP3) were generated using the representations from active tester vs. inactive driver CDNAs (A) and from inactive tester vs. active driver CDNAs (B). Size markers (base pair, bp) are indicated to the left. 


\section{Discussion}

As transcription of most genes correlates with their protein function, changes in transcription are likely to reflect changes in biochemical processes within an organism. Thus, identifying genes in anhydrobiotic tardigrades whose expression is modified by various environmental conditions is an important goal of our research. In the present study, using a combination of ESTs and RDA, we have identified dozens of differently expressed genes in Milnesium tardigradum.

Expressed sequence tags (EST) represent an effective genomic approach for rapid identification of expressed genes. Many successful EST projects have been reported for a number of species and from a variety of tissues under different environmental conditions [21-23]. Furthermore, the availability of cDNA sequences has accelerated molecular characterization of genes of interest and provided sequence information for microarray construction and genome annotation.

However, most of these EST projects subjected defined tissues or genotypes. The EST project reported in this study is designed using the whole and the same specie (M.tardigradum) but in different physiologic states: anhydrobiotic (dry) versus normal (alive) state.

RDA as a rapid PCR-based method [19] has been successfully adapted and used for the cloning of genes, which are differentially expressed between active and inactive animals. This method is particularly appropriate for application to species whose genomes and expressed sequences have been very little characterized [24].

Until now, we do not know whether any of the differentially expressed genes we have identified are responding specifically to anhydrobiosis processes or are more general in their activity. A combination of proteomic analysis and microarray technology is expected to provide insight into the specific process of gene transcription in anhydrobiotic tardigrades and may be relevant to understand how organisms tolerate extreme conditions and persist in dry state for long periods.

Among the genes identified by EST and RDA, almost half were homologous to sequences known from other species. The rest of the DNA sequences showed no significant homology to previously described genes and at present we cannot deduce any function for these genes in anhydrobiois. A detailed analysis of the function of these unknown genes however provides clues to possible mechanisms that contribute to the comprehension of anhydrobiosis.

\section{Potential application}

Understanding the desiccation-tolerance in anhydrobiotic organisms will enable us to induce or engineer tolerance in sensitive species and subsequent long-term stabilization and preservation of biological materials in dry state. This is a topic of a broad-ranging medical and commercial interest. In the medical field conservation of cells and organs is covered; the food industry will be interested in preservation and storage and the pharmaceutical industry tries to extend the shelf life of protein-based drugs and enzymes. The latter also being of interest in white biotechnology. The need for stabilization of cells in the dried or frozen state is particularly urgent in organ and tissue preservation for transportation and medical applications, as well as long term storage of autologous and heterologous tissue and organ material. For example, human blood platelets are not allowed to be stored beyond five days, therefore, shortage of fresh platelets sometimes occurs. With new techniques it may become possible to store platelets, cell lines, tissues or organs at room temperature, rather than in expensive liquid-nitrogen freezers. Also transportation could become easier.

\section{Conclusions and perspectives}

Tardigrades have hardly been the subject of detailed scientific investigations, due to the rare existence of molecular and genetic data. As a first step, in the present study we generated thousands of ESTs sequences that will be important for downstream experiments and analyses.

The ESTs and RDA sequences will be amplified and spotted onto glass slides in known locations to create microarrays or gene chips. cDNAs can be labelled with different fluorescent tags and allowed to hybridize with the DNA on the chip. The expression level of thousands of genes can be then analyzed at the same time. Subsequently, the gene expression profiles will be determined in order to identify genes that are associated with anhydrobiosis.

Beside the main focus on anhydrobiosis, we started genotyping within different members of tardigrada, mainly close relatives of Milnesium, in order to determine the molecular aspect of their anhydrobiotic phenotypes. Besides other sequences we plan to use $18 \mathrm{~S}$ rDNA and mitochondrial cytochrome oxidase sequence in- 
formation in our studies since these genes contain both conserved and variable regions. Also, this area has been targeted by most other research groups and will enable us to compare our data.

\section{References}

[1] Crowe, J. H./Hoekstra, F. A./Crowe, L. M. (1992): Anhydrobiosis. Annu. Rev. Physiol. 54, 579-599.

[2] Tunnacliffe, A./Lapinski, J. (2003): Resurrecting van Leeuwenhoek's rotifers: a reappraisal of the role of disaccharides in anhydrobiosis. Phil. Trans. R. Soc. Lond. B 358, 1755-1771.

[3] Clegg, J. S. (2001): Cryptobiosis - a peculiar state of biological organisation. Comp. Biochem. Physiol. 128B, 613-624.

[4] Jönsson, K. I./Schill, R.O. (2007): Induction of Hsp70 by desiccation, ionising radiation and heat-shock in the eutardigrade richtersius coronifer. CBP 2007, 146:456-460.

[5] Bertolani, R./Guidetti, R./Jönsson, K. I./Altiero, T./Boschini, D./ Rebecchi, L. (2004): Experience with dormancy in tardigrades. J Limnol 2004, 63(1):16-25.

[6] Potts, M. (1999): Mechanisms of desiccation tolerance in cyanobacteria. Eur. J. Phycol. 57, 4368.

[7] Ricci, C. (1998): Anhydrobiotic capabilities of bdelloid rotifers. Hydrobiologia 387 388, 321326.

[8] Alpert, P. (2000): The discovery, scope and puzzle of desiccation tolerance in plants. Plant Ecol. 151, 517.

[9] Scott, P. (2000): Resurrection plants and the secrets of the leaf. Ann. Bot. 85, 159166.

[10].Cuming, A. C. (1999): LEA Proteins. Seed Proteins 1999:753-780.

[11] Browne, J./Tunnacliffe, A./Burnell, A. (2002): Anhydrobiosis - plant desiccation gene found in a nematode. Nature 2002, 416(6876):38.

[12] Browne, J. A./Dolan, K. M./Tyson, T./Goyal, K./Tunnacliffe, A./ Burnell, A. M. (2004): Dehydration-specific induction of hydrophilic protein genes in the anhydrobiotic nematode aphelenchus avenae. Eukaryot Cell 2004, 3(4):966-975.

[13] Westh, P./Ramlov, H. (1991): Trehalose accumulation in the tardigrade Adorybiotus coronifer during anhydrobiosis. J Exp Zool 1991, 258:303-311.

[14] Crowe, L. M. (2002): Lessons from nature: the role of sugars in anhydrobiosis. Comp Biochem Physiol Part A Mol Integr Physiol 2002, 131(3):505-513.

[15] Hengherr, S./Heyer, A. G./Köhler, H. R./Schill, R. O. (2008): Trehalose and anhydrobiosis in tardigrades - evidence for divergence in responses to dehydration. FEBS J 2008, 275(2):281-288.

[16] Guidetti, R./Bertolani, R. (2005): Tardigrade taxonomy: an updated check list of the taxa and a list of characters for their identification. Zootaxa 2005, 845:1-46.

[17] Wright, J. C. (2001): Cryptobiosis 300 years on from van leuwenhoek: what have we learned about tardigrades? Zool Anz 2001, 240:563-582.

[18] Jönsson, K. I./Rabbow, E./Schill, R. O./Harms-Ringdahl, M./Rettberg, P. (2008): Tardigrades survive exposure to space in low Earth orbit. Current Biology, Vol 18, R729-R731.

[19] Frohme, M./Hoheisel, J. D. (2006): Representational difference analysis; a methodology to study differential gene expression. In Celis J (Hrsg.): Cell Biology - A laboratory handbook, 3. Ed., Elsevier, New York: Vol. 4, 113-120.
[20] Shkumatov, A./Förster, F./Liang, C./Engelmann, J./Schnölzer, M./Frohme, M./Müller, T./Schill, R. O./Dandekar, T. (submitted): Tardigrade analyzer reveals new stress adaptations, RNA elements and major tardigrade protein clusters.

[21] Denise E Abbott, D. E./Pritchard, C./Clegg, N. J./Ferguson, C./ Dumpit, R./Sikes, R. A./Nelson, P. S. (2003): Expressed sequence tag profiling identifies developmental and anatomic partitioning of gene expression in the mouse prostate. Genome Biology 2003, 4:R79

[22] Clark, M. S./corresponding Michael AS Thorne, M. A. S./Purać, J./ Grubor-Lajšić, G./Kube, M./Reinhardt, R./Worland, M. R. (2007): Surviving extreme polar winters by desiccation: clues from Arctic springtail (Onychiurus arcticus) EST libraries. BMC Genomics. 2007; 8: 475.

[23] Soza-Ried, J./Hotz-Wagenblatt, A./Glatting, K. H./del Val, C./ Bode, H./Frank, U./Hoheisel, J./Frohme, M. (submitted): The transcriptome of the colonial marine hydroid Hydractinia echinata.

[24] Grohme, M./Frohme, M./Mali, B.: PCR-based methods for differential gene expression analysis. Current Pharmaceutical Analysis (in print).

\section{Authors}

Prof. Dr. Marcus Frohme

Dr. Brahim Mali

Markus Grohme, PhD student

Weronika Wełnicz, MSc student

Technical University of Applied Sciences Wildau, Germany Faculty of Engineering/Industrial Engineering and Management Laboratory for Molecular Biology and Functional Genomics

Tel. +49 3375 508-249

marcus.frohme@tfh-wildau.de

Prof. Dr. Thomas Dandekar

University of Würzburg, Germany

\section{Dr. Martina Schnölzer}

German Cancer Research Center Heidelberg, Germany

\section{Dr. Dirk Reuter}

Oncoscience AG, Wedel, Germany

\section{Dr. Ralph O Schill}

University of Stuttgart, Germany 